\title{
Efficacy of a new combined larvicidal-adulticidal ultralow volume formulation against Aedes aegypti (Diptera: Culicidae), vector of dengue
}

\author{
Alejandro Lucia • Laura Harburguer • \\ Susana Licastro $\cdot$ Eduardo Zerba $\cdot$ Hector Masuh
}

Received: 13 November 2008 / Accepted: 18 November 2008 / Published online: 10 December 2008

(C) Springer-Verlag 2008

\begin{abstract}
A new ultralow volume formulation (ULV) containing permethrin as an adulticidal active ingredient and the insect growth regulator (IGR) pyriproxyfen as a larvicide was developed and its efficacy evaluated in a field trial in Wanda, Misiones (Argentina). Two separate study areas were sprayed: one with a ULV formulation of permethrin $15 \%$ plus pyriproxyfen $3 \%$ and the other with permethrin $15 \%$ only. A third untreated area was kept as a control. Sentinel cages containing adult mosquitoes and jars containing Aedes aegypti larvae III/IV were placed in treated and control areas. The residual activity of the formulations was tested using $20 \mathrm{~L}$ water containers. The adulticide effect of permethrin $15 \%+$ pyriproxyfen $3 \%$
\end{abstract}

A. Lucia $\cdot$ L. Harburguer $\cdot$ S. Licastro $\cdot$ E. Zerba $\cdot$ H. Masuh $(\bowtie)$ Centro de Investigaciones de Plagas e Insecticidas (CIPEIN) CITEFA-CONICET,

Juan Bautista de La Salle 4397 Villa Martelli,

Buenos Aires (1603), Argentina

e-mail: hmasuh@citefa.gov.ar

A. Lucia

e-mail: cipein@citefa.gov.ar

e-mail: alucia@citefa.gov.ar

L. Harburguer

e-mail: lharburguer@citefa.gov.ar

S. Licastro

e-mail: slicastro@citefa.gov.ar

E. Zerba

e-mail: ezerba@citefa.gov.ar

E. Zerba $\cdot$ H. Masuh

Instituto de Ingenieria e Investigación Ambiental,

Universidad Nacional de General San Martín (UNSAM),

Belgrano $35631^{\circ}$ piso San Martín, Provincia de Buenos Aires

(B1650ANQ), Argentina formulation was similar to the permethrin $15 \%$ formulation, however, the inhibition of adult emergence in the treatment with permethrin $15 \%$ never exceeded $20 \%$, whereas the inhibition of adult emergence in the treatment with permethrin $15 \%$ plus pyriproxyfen 3\% showed initial values of $96 \%$ maintaining this high level of inhibition up to 35 days after ULV spraying. Larval indexes (House and Breteau indexes) showed that a greater, long-lasting effect was obtained with the permethrin $15 \%$ plus pyriproxyfen $3 \%$ formulation.

\section{Introduction}

Dengue fever, whose principal vector is Aedes aegypti (L.), is the most important medical arbovirus disease in the world, with an estimated annual 100 million cases (Deubel and Murgue 2001). In the 1950s and 1960s, an eradication program was undertaken in Latin America which resulted in the virtual disappearance of $A$. aegypti from the region. However, the Latin American countries were not able to sustain these programs, and the vector populations returned with densities greater than those existing prior to the eradication program. Additionally, the vector is now found in areas where it had not previously been present (Gratz and Knudsen 1996).

The inability to control the spread of dengue/DHF in Latin America is a direct result of the inadequate effect and lack of sustainability of the control campaigns undertaken by government teams. These campaigns have not succeeded in reducing the population density of the vector to the point that the transmission of the virus is interrupted (Chavasse and Yap 1997).

Because there is no dengue surveillance, capability to detect an increased incidence of the vector to allow a timely 
response, most programs' reaction comes too late to alter the epidemic's course (WHO 1995a). Monitoring of A. aegypti oviposition sites and performing preventive larviciding are the principal actions for $A$. aegypti control activities (WHO 1995b). Ovitraps could be a cost-effective method of monitoring population fluctuations and to detect a peak of vector density and thus apply a control measure in the right moment (Masuh et al. 2008).

The most common way of controlling $A$. aegypti is larval source reduction in domestic habitats. Applying larvicides in containers that cannot be eliminated is still considered a priority during control programs. The main larvicide used over the past 30 years is the organophosphorus compound temephos (Chavasse and Yap 1997). At present, the main treatment used for adult control is ground application of space sprays delivering a minimum volume of insecticide formulation per unit area (ultralow volume, ULV; PAHO 1994). These treatments with adulticides are recommended both for preventive actions as well as for dengue outbreaks. Nevertheless, space treatments like ULV lack efficacy on larvae inside and outside the dwellings. On the other hand, the application of larvicides in containers has to deal with the diversity and multiplicity of larval habitats (Matthews 1996).

The weak points of the current $A$. aegypti control strategies are: (1) insufficient control of larvae in field conditions; (2) limited effectiveness of insecticidal treatments in open areas due to insufficient residual effect, the larvicides used and poor penetration inside dwellings; (3) minimal participation by communities (the current efforts to stimulate and mobilize communities are directed at reorganizing the environment, which is not always successful); and (4) vector control activities are only partially included in vertically directed, centralized, and costly programs.

The above analysis suggests the need to develop effective vector control programs to interrupt the transmission of dengue. Innovation in the area of insecticidal tools is required to strengthen weak aspects of the current chemical control and thus progress toward reducing mosquito populations. At this time, considerable efforts are made to promote the use of environmental friendly insecticides, using different approaches to improve or even replace today's control strategies (Sonthaya Tiawsirisup et al. 2007).

The development of a new insecticidal formulation effective against both adult and immature aquatic forms of mosquitoes could be particularly useful for improving spatial treatments for the control of outdoor vector populations.

In this paper we present results on the field evaluation of a new ULV formulation comprised by permethrin and pyriproxyfen that is effective against adult and immature aquatic forms of mosquitoes. Mixed formulations of a larvicide and adulticide could be a new alternative for $A$. aegypti control strategies in open areas.

\section{Materials and methods}

Study site

Wanda $\left(25^{\circ} 57^{\prime} 51.85^{\prime \prime} \mathrm{S} ; 54^{\circ} 35^{\prime} 22.90^{\prime \prime} \mathrm{W}\right)$ is a subtropical city with 12.779 inhabitants located $50 \mathrm{~km}$ south of Puerto Iguazú in the Province of Misiones (Argentina),

Two areas of approximately 36 ha each, completely separated by green areas, were used for ULV treatments with permethrin $15 \%+$ pyriproxyfen $3 \%$ (AL formulation) and permethrin 15\% (A formulation). A third untreated area was kept as a control zone. The three areas chosen had similar socioeconomic characteristics and natural barriers such as rivers or large green spaces acting as buffer zones.

\section{Chemicals}

Formulation $A$ Permethrin 15\% (3-phenoxyphenyl)methyl 3-(2,2-dichloroethenyl)-2,2-(dimethyl cyclopropane carboxylate), cis:trans relationship 45:55, was provided as an emulsifiable concentrate (EC) by Chemotecnica S.A. (Argentina).

Formulation AL Experimental formulation; permethrin 15\% plus pyriproxyfen 3\% (2-(1-methyl-2-(4-phenoxyphenoxy) ethoxy)pyridine) as an emulsifiable concentrate (EC) was formulated by Chemotecnica S.A.(Argentina).

Polyethyleneglycol 1000 was used as an antievaporant for ULV treatments.

\section{Biological material}

We used an insecticide-susceptible strain of $A$. aegypti (Rockefeller strain). The strain was reared as described in previous reports by our laboratory (Lucia et al. 2007), at the laboratory of the NOA region for Vector Control Program (National Ministry of Health) in Villa Libertad (Misiones, Argentina).

\section{ULV treatments}

A cold vehicle-mounted generator, Curtis Dyna-Fog 2PTM ULV Maxi-ProTM (Westfield, IN, USA), was used for ULV application. The flow was regulated to release $1 \mathrm{~L}$ of mixture every $2 \mathrm{~min} 40 \mathrm{~s}$, the time taken to spray 1 ha. Under these conditions, $10 \mathrm{~g}$ of permethrin/ha were applied in the area treated with the formulation $\mathrm{A}$, and $10 \mathrm{~g}$ of permethrin $+2 \mathrm{~g}$ pyriproxyfen/ha were sprayed in the area 
treated with the formulation AL. Applications were carried out during the peak of mosquito flight activity (either before dawn or after sunset). Spray activities were performed on March 19, 2007.

\section{Monitoring A. aegypti populations}

Population levels of $A$. aegypti larvae were determined by visual observation using larval sampling according to PAHO (PAHO 1994). House index (HI) defined as the percentage of houses infested with larvae and/or pupae and Breteau index (BI) defined as the number of positive containers per 100 inspected houses were determined to estimate vector abundance. Entomological studies were carried out in the village for 10 weeks, from March 7 to May 9, 2007.

From each of the three areas selected, a central zone of $4 \times 4$ blocks was used to carry out the vector monitoring. Each block has more or less five houses separated by a green area, which makes a total of approximately 100 houses. To evaluate infestation with larvae, 20 houses were randomly selected. HI and BI were determined weekly starting 3 weeks before the ULV application and ending after the treatment, until the population levels returned to pretreatment values.

\section{Adult and larval bioassay}

Field bioassays were performed according to WHO's protocols (Reiter and Nathan 2003; WHO 2005) with minor modifications.

Cylindrical screened sentinel cages, built with 18-mesh nylon and $15 \mathrm{~cm}$ long $\times 3 \mathrm{~cm}$ diameter were placed in each central zone.

A few hours before ULV spraying, ten adults $(50 \%$ of each sex), aged 24-36 h and fed on raisins, were transferred to each cage.

Two groups of ten cages were randomly hung outside the dwellings at 3 and $6 \mathrm{~m}$ from the pulverization line and at $1.5 \mathrm{~m}$ from the floor. Five additional cages were placed in the control area.

In addition, five plastic $250 \mathrm{ml}$ jars $(7.5 \mathrm{~cm}$ diameter $)$ containing 15 late third or early fourth instar $A$. aegypti larvae and $200 \mathrm{ml}$ tap water were placed oustide each selected house at $5 \mathrm{~m}$ from the pulverization line.

Both screened cages and plastic jars were taken back to the laboratory $30 \mathrm{~min}$ after ULV spray application. They were kept at room temperature. Hydration was provided to the cages, and adult mortality in the treated cages was assessed at both 2 and $24 \mathrm{~h}$. The 250-ml plastic jars were inspected daily to determine the inhibition of adult emergence.

The test finished when no statistically significant larvicidal effect was observed in terms of adult emergence inhibition between the treated recipients and untreated controls.

Adult emergence inhibition (EI \%) was calculated as shown below and adjusted for larval or pupal mortalities in the corresponding controls according to Mulla et al. (1974)

$\mathrm{EI}(\%)=100-100(T / C)$

where $T$ is the percentage of emergence in treated containers, and $C$ is the percentage of emergence in control containers.

\section{Residual bioassay}

White plastic artificial $20 \mathrm{~L}$ containers $(29 \mathrm{~cm}$ diameter) filled with tap water were placed side-by-side to the $250 \mathrm{ml}$ plastic jars. On the day before ULV treatment, 15 late third or early fourth instar A. aegypti larvae were placed inside the vessels. Larval food was provided. After pulverization, the 20-L containers were covered with nylon gauze to prevent emerged adults from escaping or other insects from entering and kept in field conditions under a roof. Once a week, the emerged adults and the larvae and pupae surviving from the previous week were removed from the treated and control containers together with approximately $100 \mathrm{ml}$ water and put into new $250 \mathrm{ml}$ jars and taken to the laboratory to assess adult emergence. Fifteen fresh late third or early fourth instar $A$. aegypti larvae were introduced into the containers. The water level in the containers was kept constant for water loss or evaporation, and the entire operation was repeated each week until no adult emergence inhibition effect was seen on the fresh larva.

\section{Statistical analysis}

The values of EI for each replicate in each treatment and in the controls were calculated on each day of observation. Data were analyzed using one-way analysis of variance (ANOVA), and means were compared by Student's $t$ test using the computer software Instat V. 3.01 for Windows (Graphpad Software, San Diego, CA, USA).

The values of adult mortality of each replicate in each treatment were calculated. Data were analyzed by multifactor analysis of variance (ANOVA) and analyzed $a$ posteriori by Tukey HSD mean multiple comparison test using Software STATGRAPHICS Plus for Windows Version 4.0 - Corp. SGWIN $\mathrm{P}^{\circledR}$. A value of $p<0.05$ was considered statistically significant.

\section{Results and discussion}

Although the principal action for A. aegypti control is larviciding of oviposition sites, especially in urban areas, during emergence situations, the ULV application was and 
still is, the fundamental control measure taken (Chadee 1985; Perich et al. 1992). Unfortunately, many of the campaigns to reduce vector populations had not been successful.

Tidwell et al. (1994) already pointed out the possible advantages of combining adulticidal and larvicidal active ingredients in spatial treatments. An attempt to increase the larvicidal effect of pyrethroid ULV formulations on different mosquito species was previously performed by mixing Pesguard PS102 and Bti in an aqueous base in the tank of a sprayer machine (Yap et al. 1997).

Wanda is a small town at risk of dengue located in the northeast part of Argentina, where the vector is well established. The occurrence of larvae and adult $A$. aegypti in most of the houses was established by the inspectors of the National Program of Vector Control of Argentina. More than $90 \%$ of the mosquitoes collected near or inside the houses were identified as A. aegypti (WHO 1995b). No attempts were made to identify the remaining collected mosquitoes although most of them were probably Culex pipiens.

Adult $A$. aegypti mortality for all the evaluated treatments is shown in Fig. 1. There were no significant differences $\left(P_{\text {value }}=0.07\right)$ in adult mortality observed 2 and $24 \mathrm{~h}$ after the treatments. There were also no significant differences $\left(P_{\text {value }}=0.25\right)$ between the adult mortality observed in cages exposed at 3 and $6 \mathrm{~m}$ from the ULV spraying application line. Furthermore, no significant differences $\left(P_{\text {value }}=0.20\right)$ in adult mortality were observed between the treatments using the formulation $\mathrm{A}$ and $\mathrm{AL}$.

It can be concluded that both formulations, $\mathrm{A}$ and $\mathrm{AL}$, had the same adulticidal effect, indicating that pyriproxyfen has no antagonist side effects on permethrin. The results also suggested that the adulticide effect of the application is immediate and did not increase at $24 \mathrm{~h}$. The continued exposure of the adults in the treated cages did not generate any additional mortality. Keeping the adults in the exposed cage could be a methodology to bear in mind that differs from the one suggested by WHO (Reiter and Nathan 2003), which is transferring adults from the treated cages to a maintenance cage and generating an additional stress effect.

No significant differences in adult emergence inhibition (EI \%) were observed between the 20-L and 250-ml recipients used for the treatment with $\mathrm{AL}$ formulation $\left(P_{\text {value }}=0.06 ; T 2.175\right)$ and A formulation $\left(P_{\text {value }}=0.76 ; T\right.$ 0.318 ; Fig. 2). In Fig. 3, it can be seen that the values of $\mathrm{EI} \%$ for the $20-\mathrm{L}$ containers located in the area treated with formulation A were never higher than $20 \%$ and decreased with posttreatment time until day 21 where EI\% was almost zero. On the other hand, the EI\% in the containers located in the area treated with formulation AL had an initial mean value of $96 \%$ and maintained a high level of EI\% up to 35 days after the ULV spraying. At this point, EI\% reached a value of $71 \%$, but a week later, the efficacy of the product was quickly reduced to a value of $2 \%$. The weekly values of $\mathrm{EI} \%$ for $A$. aegypti larvae located in both treatment areas were always statistically different $(P$ values $<0.05)$. This difference between treatments was observed until the value of $\mathrm{EI} \%$ for the treatment with formulation $\mathrm{AL}$ was almost zero. The larvicidal effect, measured as the inhibition of adult emergence, in the area treated with formulation $\mathrm{A}$,
Fig. 1 Adult mortality of A. aegypti caged mosquitoes exposed to permethrin $15 \%$ (A formulation) and pyriproxyfen $3 \%+$ permethrin $15 \%(\mathrm{AL}$ formulation). Values are the mean of ten replicates $\pm \mathrm{SD}$

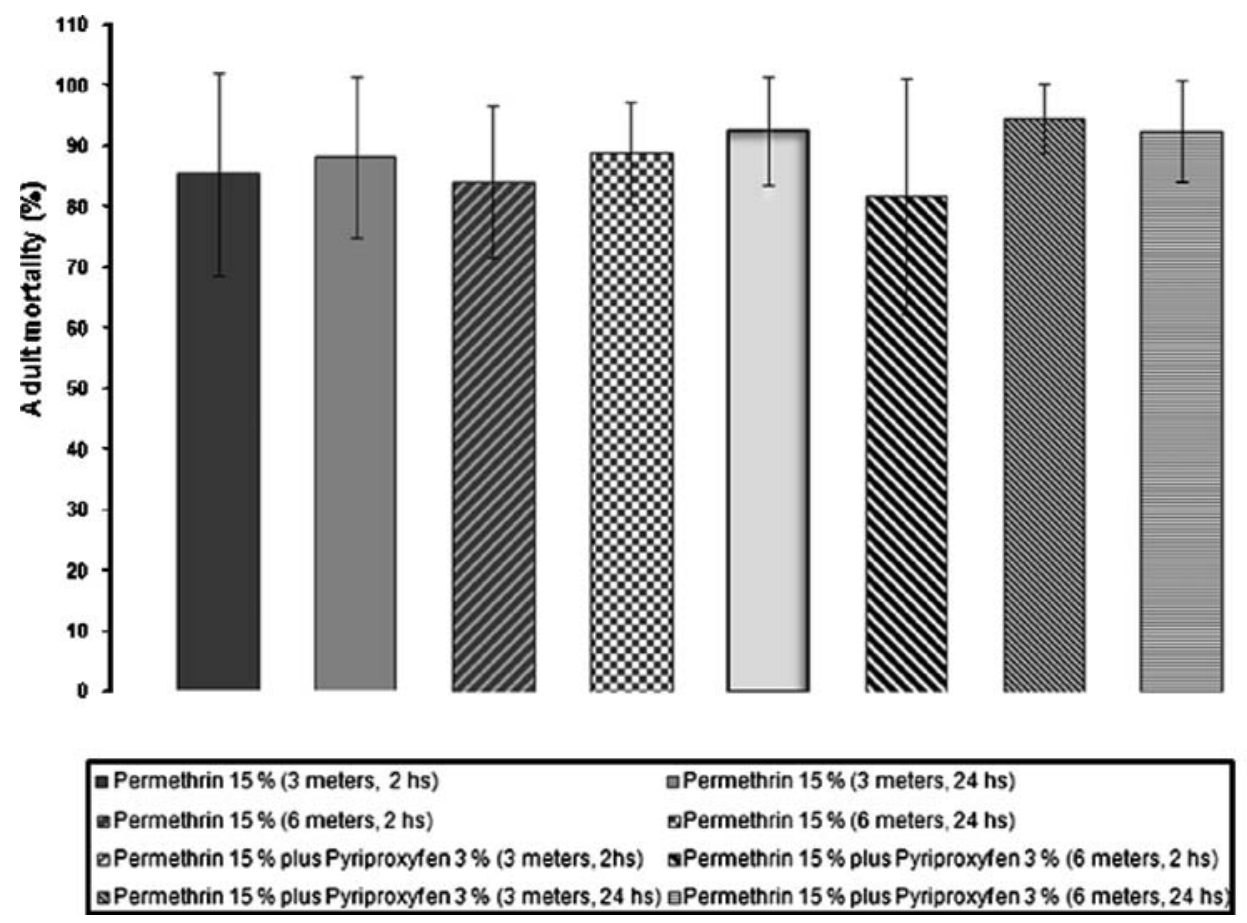


Fig. 2 Inhibition of adult emergence of $A$. aegypti larvae exposed to permethrin $15 \%$ (A formulation) and pyriproxyfen $3 \%+$ permethrin $15 \%$ (AL formulation) in $20 \mathrm{~L}$ and $250 \mathrm{~mL}$ containers. Values are the mean of five replicates \pm SD

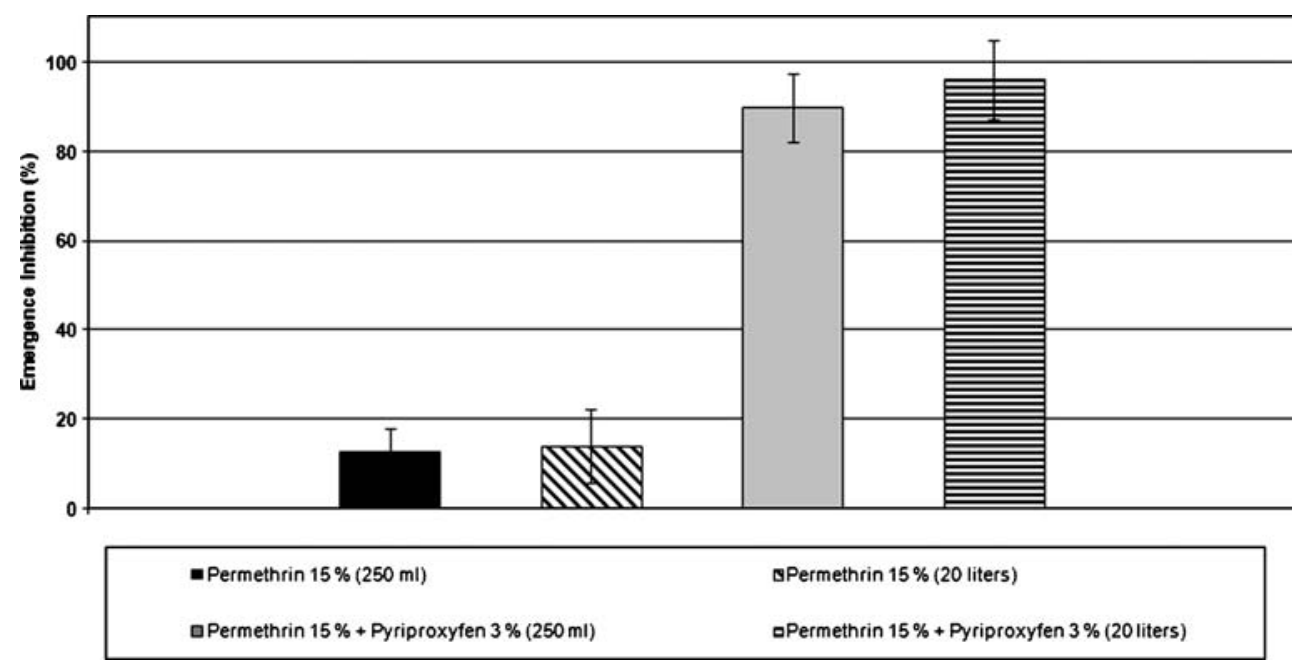

was always low. For the area treated with the formulation $\mathrm{AL}$, it was almost $100 \%$, and maintaining this value up to 35 days indicates a promissory effect given by the IGR.

Comparing the $20 \mathrm{~L}$ and $250 \mathrm{ml}$ recipients used for larvicidal treatments we found that the size of the recipients had not a diluting effect on the insecticide, which could have affected the values of EI\%. Therefore, spatial ULV treatments with permethrin and pyriproxyfen could have a very good performance on a wide range of containers.

Entomological surveillance showed that in the three areas assayed, larval indexes values were very high prior to the treatment, which is characteristic of this area of Argentina (Masuh 2003). BI values were higher than 80 in all the areas. The posttreatment readings in the control area were higher than the pretreatment values, reaching a value close to 140 (Fig. 4). With respect to the number of inspected houses in each locality, it depends on the required precision, the percent infestation, and the disponibility of manpower. According to PAHO, a $25 \%$ of the total houses could give an idea of the infestation with the vector. Thus, in areas of very high infestation, 20 of each 100 houses distributed in an aleatory form were taken for entomological evaluation in each central area.

In order to evaluate the insecticide impact, the entomological evaluations were followed until pretreatment values were reestablished. It took almost 3 weeks for the pretreatment values to be reestablished in the area treated with formulation A, showing a minimal BI value of 69 1-week after application. On the other hand, about 5 weeks were needed to restore pretreatment levels in the area treated with formulation $\mathrm{AL}$, with the lowest $\mathrm{BI}$ value of 50 remaining constant for 1 week. The lowest BI values were
Fig. 3 Adult emergence inhibition of $A$. aegypti larvae exposed to permethrin 15\% (A formulation) and pyriproxyfen $3 \%+$ permethrin $15 \%$ (AL formulation) in $20 \mathrm{~L}$ containers. Values are the means of five replicates \pm SD for each day of observation

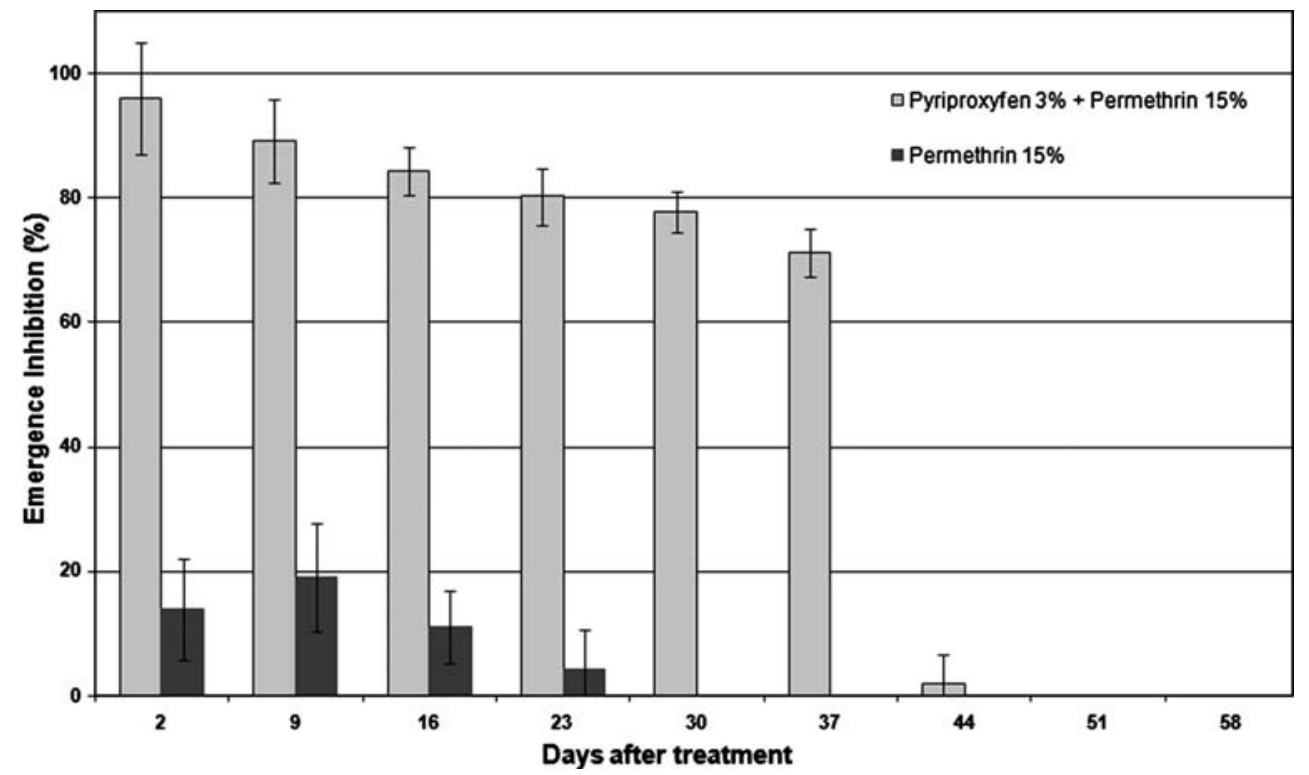


Fig. 4 Larval abundance (BI) of A. aegypti for the areas treated with permethrin $15 \%$ (A formulation) and pyriproxyfen $3 \%+$ permethrin 15\% (AL formulation) in the field trial carried out in Wanda between March and May 2007. The arrow indicates the time of application

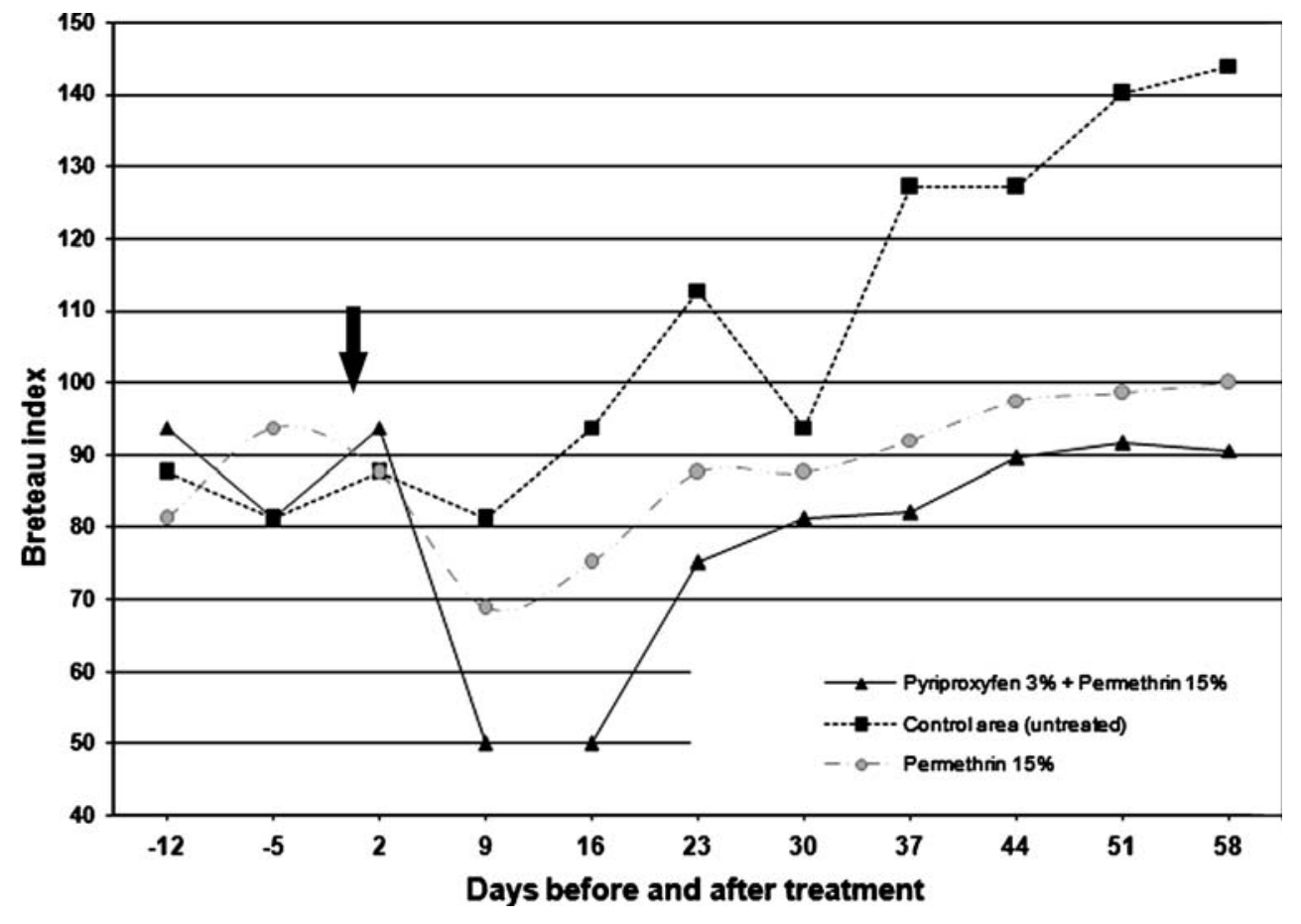

always observed in the area assigned to the treatment with formulation $\mathrm{AL}$, with a difference of about 30 to 40 compared to the control zone and among 10 to 20 with respect to the treatment with formulation A. Similar results were observed with the values for HI (Fig. 5).

After the treatment with the ULV formulation of permethrin or permethrin plus pyriproxyfen, 3 and 5 weeks were needed, respectively, to restore the original indexes indicating a better performance of the combined formulation.
The effective control activity against $A$. aegypti adults and larvae suggests that the new formulation could be a new successful alternative for controlling dengue vector populations in open areas. Besides, pyriproxyfen had been considered recently by the World Health Organization under its Pesticides Evaluation Scheme (WHOPES) at a recommended dosage of $0.01 \mathrm{mg} / 1$ for controlling diseasecarrying mosquitoes in drinking-water containers (WHO 2003, 2006a, b).
Fig. 5 Larval abundance (HI) of $A$. aegypti for the areas treated with permethrin $15 \%$ (A formulation) and pyriproxyfen $3 \%+$ permethrin $15 \%$ (AL formulation) in the field trial carried out in Wanda between March and May 2007. The arrow indicates the time of application

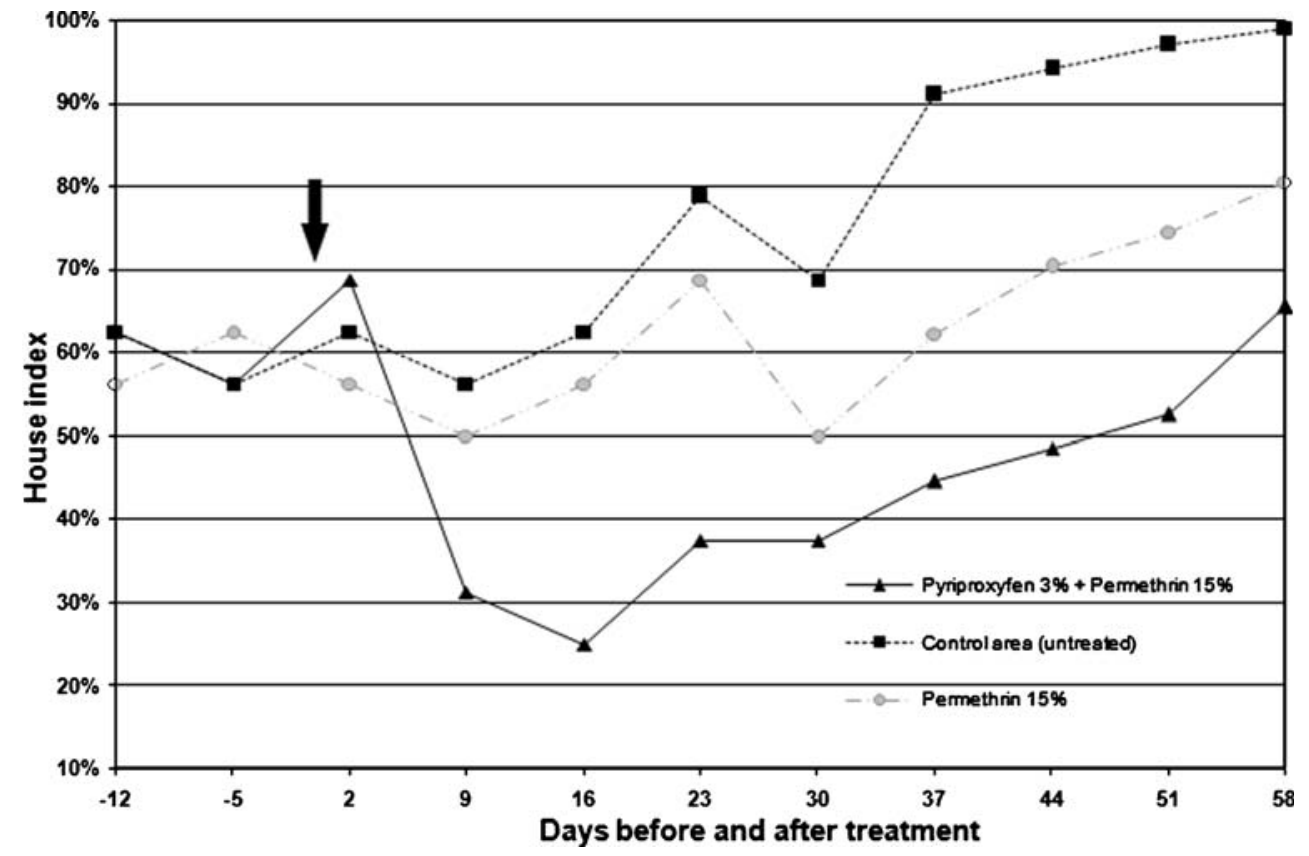


Acknowledgments We are especially grateful to all the people who worked in the field trial, Mr. Carlos Vega, Chief of NOA region of Vector Control Program (National Ministry of Health), Mr. Sandro Lopez, Mr. Jorge Britez and Mrs. Norma Gauto.

This research received financial support from the Agencia Nacional de Promoción Científica y Tecnológica (Argentina) and Chemotécnica S.A. (Argentina).

\section{References}

Chadee DD (1985) An evaluation of malathion ULV spraying against caged and natural populations of Aedes aegypti in Trinidad, West Indies. Cahiers ORSTOM Series Entomol and Med Parasitol 23:71-74

Chavasse DC, Yap HH (1997) Chemical Methods for the Control of Vectors and Pests of Public Health Importance. WHO/CDT/ WHOPES/97.2 pp 27, Geneva, Switzerland

Deubel V, Murgue B (2001) The Encyclopedia of ArthropodTransmitted Infections, Edited by M.W. Service. CAB International, New York, pp 133

Gratz N, Knudsen B (1996) The rise and spread of dengue, dengue hemorrhagic fever and its vectors. A Historical Review (up to 1995). CTD/FIL (DEN) 96.7, WHO

Lucia A, Gonzalez Audino P, Seccacini E, Licastro S, Zerba E, Masuh H (2007) Larvicidal effect of Eucalyptus grandis essential oil and turpentine and their major components on Aedes aegypti larvae. J Am Mosq Control Assoc 23:299-303

Masuh H, Arnstein de Licastro S, Lopez PA, Vega C, Zerba E (2003) Field evaluation of a smoke generating formulation containing beta-cypermethrin against the dengue vector in Argentina. J Am Mosq Control Assoc 19:53-57

Masuh H, Seccacini E, Zerba E, Licastro S (2008) Aedes aegypti (Diptera: Culicidae): monitoring of populations to improve control strategies in Argentina. Parasitol Res 103:167-170

Matthews GA (1996) Application of insecticides in dengue control. Pesticide Outlook 2:25-30

Mulla MS, Darwazeh HA, Norland RL (1974) Insect growth regulators: evaluation procedures and activity against mosquitoes. J Econ Entomol 67:329-332

PAHO (1994) Dengue and dengue hemorrhagic fever in the Americas: Guidelines for prevention and control. Scientific Publication 548:28-29
Perich MJ, Davila G, Turner A, García A, Nelson M (1992) Behavior of resting Aedes aegypti (Culicidae:Diptera) and its relation to ultra-low volume adulticide efficacy in Panamá city, Panamá. J Med Entomol 37:541-546

Reiter P, Nathan MB (2003) World Health Organization. Report of the WHO Informal Consultation on the evaluation and testing of insecticidas - Guía para la evaluación de la eficacia del rociado espacial de insecticidas para el control del vector del dengue. (WHO/CTD/WHOPES/IC/96.1). Geneva, Switzerland

Tiawsirisup S, Nithiuthai S, Kaewthamasorn M (2007) Repellent and adulticide efficacy of a combination containing 10\% imidacloprid and 50\% permethrin against Aedes aegypti mosquitoes on dogs. Parasitol Res 101:527-531

Tidwell MA, Williams DC, Gwinn GA, Pena CJ, Tedders SH, Gonzalvez GE, Mekuria Y (1994) Emergency control of Aedes aegypti in the Dominican Republic using the Scorpion ${ }^{\mathrm{TM}}$ ULV forced-air generator. J Am Mosq Control Assoc 10:403-406

WHO (World Health Organization) (1995a) Dengue and Dengue Hemorrhagic Fever in the Americas: Guidelines for Prevention and Control. PAHO Washington DC, USA; Scientific Publication $\mathrm{N}^{\circ} 548$

WHO (World Health Organization) (1995b) Guidelines for Dengue Surveillance and Mosquito Control. Western Pacific Education in Action Series, Manila $N^{\circ} 8$, Geneva, Switzerland

WHO (World Health Organization) (2003) Pyriproxyfen in drinking water. Background document for preparation of WHO Guidelines for drinking-water Quality. Geneva (WHO/SDE/WSH/03-04/ 113) Switzerland

WHO (World Health Organization) (2005) Report of the Eighth WHOPES Working Group Meeting. Geneva. Guidelines for laboratory and field testing of mosquito larvicides (WHO/CDS/ WHOPES/GCDPP/2005.13). Geneva, Switzerland

WHO (World Health Organization) (2006a) Pesticides and their application for the control of vectors and pests of public health importance, Department of Control of Neglected Tropical Diseases, Pesticide Evaluation Scheme, 6th ed. (WHO/CDS/ NTD/WHOPES/GCDPP/2006.1). Geneva, Switzerland

WHO (World Health Organization) (2006b) Pyriproxyfen. 4phenoxyphenyl (RS)-2-(2-pyridyloxy)propyl ether. Geneva, World Health Organization (WHO Specifications and evaluations for Public Health Pesticides). Geneva, Switzerland

Yap HH, Chong AS, Adanan CR, Chong NL, Rohaizat B, Abdul Malik Y, Lim SY (1997) Performance of ULV formulations (Pesguard $^{\mathrm{TM}}$ 102/Vectobac TM 12AS) against three mosquito species. J Am Mosq Control Assoc 13:384-388 